\title{
Hydrothorax after Central Venous Catheterization
}

\author{
C. J. RUDGE， M. BEWICK， I. MCCOLL
}

1 1. dextrose/saline. The blood pressure remained steady at $90 / 60$ $\mathrm{mm} \mathrm{Hg}$, but the patient became increasingly dyspnoeic (respiration $30 / \mathrm{min}$, pulse $140 / \mathrm{min}$ ) four hours postoperatively. On examination she was found to be acidotic, ketotic, and severely dyspnoeic. Her right hemithorax was dull to percussion and breath sounds were diminished. The infusion was immediately stopped, and a chest $x$-ray film showed complete opacification of the right hemithorax. Immediate tapping of the chest yielded clear slightly blood-stained fluid, and formal aspiration produced $2,300 \mathrm{ml}$ of similar fluid. Simultaneously a peripheral infusion was set up, and action taken to control her hyperglycaemia and ketoacidosis. Her respiratory embarrassment responded rapidly to drainage of her hydrothorax, and the intravenous catheter was removed with no ill effects. She subsequently made a good recovery and was discharged two weeks later-though her ateriovenous fistula had long since ceased to function.

\section{Introduction}

The insertion of an intravenous catheter for the measurement of central venous pressure has increasingly become part of the routine investigation and management of the seriously ill patient. It is being used for the control of emergency blood and fluid replacement in patients with, for example, gastrointestinal haemorrhage or those undergoing major surgery, and for the monitoring of fluid requirements postoperatively. Northfield and Smith (1970) pointed out its value in early detection of repeated "hidden" gastrointestinal bleeding. In the long-term situation a central venous line allows maintained parenteral feeding, and Latimer (1971) pointed out its value in the longterm administration of antibiotics as in subacute bacterial endocarditis. Complications associating with central venous catheters are well documented, in particular both local and general sepsis, catheter embolization, pericardial and mediastinal haemorrhage, and pneumothorax having been extensively reported. Four cases are reported here where damage to neck veins ensued, resulting in a hydrothorax developing in three cases.

\section{Case 1}

A 13-year-old girl had been a diabetic for six and a half years and was controlled on insulin. The control was unstable and each episode of hyperglycaemia and hypoglycaemia was managed with great difficulty as a result of her poor peripheral veins, which resulted in problems of venipuncture and intravenous infusion. Accordingly she was admitted for insertion of an arteriovenous fistula in her left arm by autogenous saphenous vein graft in order to facilitate these manoeuvres. Immediately after induction of anaesthesia a 12 -in $(30-\mathrm{cm})$ Intracath was inserted in the right subclavian vein by percutaneous supraclavicular puncture. Blood was aspirated easily along the catheter before the infusion was started. The operation itself was technically difficult and flow was established through the fistula with great difficulty. A $500 \mathrm{ml}$ infusion of Hartmann's solution was given intravenously during the operation. At the end of the operation her condition was satisfactory (pulse $100 / \mathrm{min}$, blood pressure $90 / 40 \mathrm{~mm} \mathrm{Hg}$ ). In an effort to improve peripheral flow through the graft, heparin 10,000 units was given intravenously together with 11 . of Rheomacrodex and

Guy's Hospital, London SE1 9RT

C. J. RUDGE, M.B., B.S., House Surgeon, Professorial Unit

M. BEWICK, F.R.C.S., Senior Lecturer, Department of Surgery

I. MCCOLL, M.S., F.R.C.S., Professor of Surgery

\section{Case 2}

A 5-year-old girl weighing $17 \mathrm{~kg}$ was admitted with transposition of the great arteries and an atrialseptal defect, diagnosed shortly after birth. She underwent a Mustard repair for total transposition, with good immediate postbypass function. Her condition was fair for 12 hours, at which stage she underwent a hypotensive episode which responded well to pressor amines given through a central venous catheter-12-in (30-cm) Intracath-inserted percutaneously in her right subclavian vein. Six hours later she developed a bradycardia of 20/min, severe hypotension, and circulatory collapse. This was treated as before with pressor amines, but on this occasion with no response. At the time she was being ventilated manually, and her endotracheal tube was adjusted or changed on several occasions. It was also observed that blood could no longer be aspirated from the central venous line, and several attempts were made to flush it. During the course of her collapse she had been given $100 \mathrm{ml} 8.4 \%$ sodium bicarbonate through the same line, and an approximately equal volume of other drugs and fluids. Forty minutes later the anaesthetist observed difficulty with the manual ventilation, together with moist sounds from the chest. Fluid was suspected in the right hemithorax, and immediate thoracotomy showed $200 \mathrm{ml}$ of clear slightly bloodstained fluid in the right pleural cavity and $50 \mathrm{ml}$ of similar fluid in the mediastinum. The central venous line was noted to be in the pleural cavity and was removed. A thoracotomy drain was left in situ. After this she made a good recovery and was discharged home 19 days postoperatively with good cardiac function.

It appears that at the time of the initial hypotensive episode the catheter was positioned correctly, as judged by the prompt response to pressor amines given intravenously through it. It is possible that during the rather hectic resuscitative procedure of the second episode the catheter became dislodged with the result that the sodium bicarbonate and other fluids given during and immediately after the collapse were administered into the pleural cavity. The first evidence of a pleural effusion was the observation by the anaesthetist of progressive difficulty with manual ventilation.

\section{Case 3}

A 28-year-old woman was admitted, severely shocked, as a result of stab wounds to the abdomen and chest. On admission her pulse was $100 / \mathrm{min}$, blood pressure $70 / 30 \mathrm{~mm} \mathrm{Hg}$. Immediate intravenous resuscitation was begun using a peripheral vein before laparotomy. This showed hemisection of the transverse colon, five perforations of the small bowel and the mesentery, with severe faecal contamination. Several litres of blood were in the peritoneum. The bowel and mesentery were sutured, and the abdomen was closed. The chest wound was immediately above the left nipple. This was explored. A track was found entering the pericardial sac but the ventricle was intact. Formal thoracotomy was not performed and a pericardial drain was inserted. Repeat two-hourly chest $x$-ray films showed no evidence of haemothorax or haemopericardium. During the course of 
this operation an attempt was made to put a central venous catheter into the right external jugular vein-this failed, but resulted in a local haematoma.

One day postoperatively a $24-$ in $(61-\mathrm{cm})$ intravenous catheter was inserted in the right median basilic vein by cut-down. She made satisfactory progress until the fifth postoperative day when her general condition deteriorated severely and the central venous pressure recordings became "erratic." A swelling appeared at the root of the neck and the right upper chest, and a large right pleural effusion developed together with a much smaller left pleural effusion. The anterior mediastinum and the root of the neck were explored, and showed oedematous tissues with no induration, pus, or haematoma. Drains were inserted in both pleural cavities and the mediastinum. Six hours postoperatively the possibility of a misplaced central venous catheter was considered and a coloured marker dye injected into the catheter was seen to drain via the right thoracotomy tube almost immediately. Injection of radio-opaque medium via the catheter showed extravascular extrusion of medium in the neck (fig. 1).

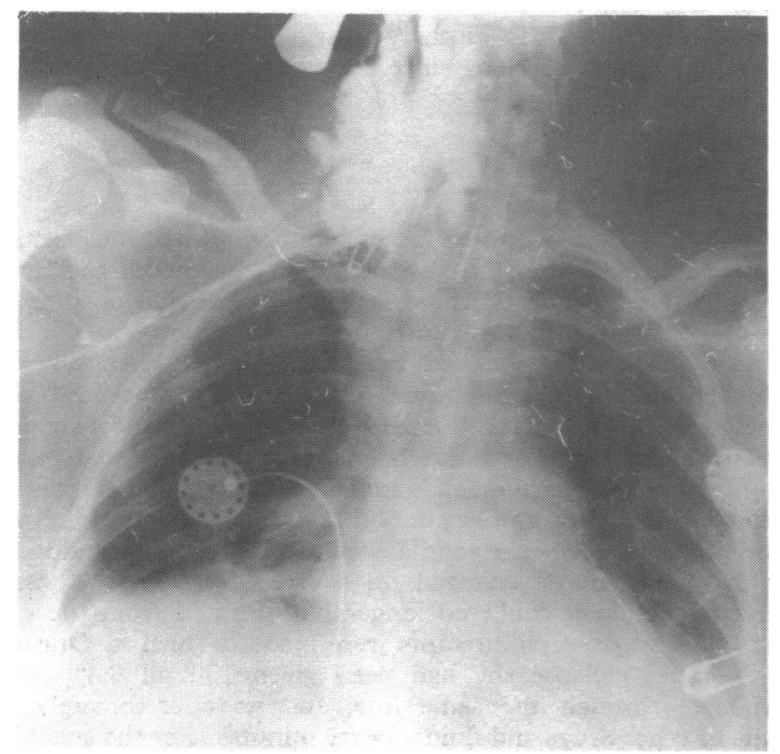

FIG. 1-Case 3. Opaque medium in tissues of right side of neck.

Accordingly the catheter was immediately removed. The possibility of further exploration was borne in mind, but the patient's general condition remained satisfactory and there was no evidence of further accumulation of pleural effusion. She thereafter made a progressive recovery, and was discharged 34 days after admission.

In this case the extensive nature of the initial injuries and the operative procedures complicated the picture, but there seems little doubt that the tip of the catheter was lying extravascularly in the neck tissues, and that the large right-sided pleural effusion could be attributed to this. The previous damage to the neck veins during the attempted insertion of the external jugular line may have been a contributing factor.

\section{Case 4}

A 28-year-old girl in renal failure had a 24-in $(61-\mathrm{cm})$ Intracath inserted by a percutaneous puncture through the left antecubital vein. Insertion was completely uneventful and for the next 12 hours she had a large quantity of fluid through the vein with no clinical abnormality. About 24 hours postoperatively while on haemodialysis it was noticed that the left side of the neck was swelling (fig. 2) and a chest $x$-ray film showed that where previously the catheter had been in her right atrium it had now become withdrawn so the tip was abutting on the arch of the left subclavian vein and presumably had perforated it. Stopping the drip caused no further increase in the swelling, and after removal the swelling disappeared in two to three days.

There was no previous history of trauma to the veins on this side of the neck, but it does seem that even an Intracath lying against the side of a vein can, in a matter of hours, perforate that vein.

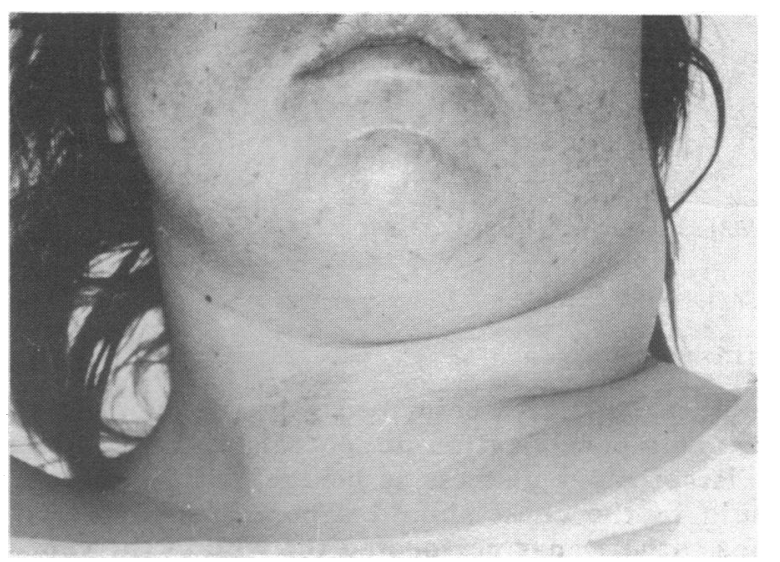

FIG. 2-Case 4. Swellings in left supraclavicular fossa due to rupture of subclavian vein.

\section{Discussion}

Despite the increasing emphasis being placed on the use of central venous lines in both acute and chronic situations, their use is not without risks, some of which are potentially lethal.

Probably the best recognized and most documented complication is that of infection. Varying reports quote different incidences of infection, but certainly unless strict aseptic precautions are used at the time of setting up the central venous line, and good care taken of the catheter site during its time in situ, a high proportion of catheter tips will show signs of infection. All catheter tips should be cultured on removal (Wilmore and Dudrick, 1969; Bolasny et al., 1970; Colvin et al., 1972; Darrell and Garrod, 1969). Henzel and DeWeese (1971) pointed out that the design of some indwelling catheters is such that a portion of the catheter may be accidentally detached as a catheter embolus with dangerous consequences. Thrombus formation and embolization in relation to catheters has been described by Doering et al. (1967) and Wellman et al. (1968). Unilateral and bilateral pneumothoraces have been reported by English et al. (1969), Walker and Saunders (1969), and Arnold et al. (1973) after internal jugular and subclavian vein cannulation and venepuncture.

Henzel and DeWeese (1971), Adar and Mozes (1971), and Thomas et al. (1969) reported perforation of the great veins of the neck and the chambers of the heart during insertion of the catheter.

Mahaffey and Witherspoon (1966), Jernigan et al. (1970), Aulebacher (1970), and Adar and Mozes (1970) pointed out the dangerous complication of haemothoraces or hydrothoraces developing after insertion of these catheters.

In all types of catheters awareness of the possible complications is the mainstay of their prevention, and it is for this reason that the above cases have been described. Study of the previous reports show that in each case there were early warning signs of the developing situation that went unrecognized. Adar and Mozes (1970) noted erratic behaviour of the central venous pressure measurements, while Mahaffey and Witherspoon (1966) reported on a patient who failed to respond initially to thiopentone sodium given via the central venous line, and then to suxamethonium chloride. An hour later she developed signs of respiratory embarrassment. Respiratory distress was also the presenting sign in the cases described by Jernigan et al. (1970), Aulebacher (1970), and Arnold et al. (1973).

The diagnosis and treatment of this condition are worthy of consideration. In common with other complications a high index of suspicion is possibly the single most important feature (Henzel and DeWeese, 1971). Any sudden or unexplained deterioration in the general condition of a patient with a central venous pressure line associated with the neck veins, and in 
particular any evidence of progressive respiratory embarrassment, must arouse suspicion of hydrothorax or haemothorax. An early danger signal that can easily be overlooked is the failure of the patient to respond to fluids and drugs administered via the catheter (cases 1 and 2). The time factor is not constantdamage to the vein wall may occur some hours or days after insertion of the catheter (cases 3 and 4).

On examination of the patient the physical signs of respiratory distress and fluid in the pleural cavity are obvious. Immediate investigations-depending on the urgency of the situationcommence with a plain chest $x$-ray film. This may be of value in that not only will the size and situation of the effusion be seen, but also the site of the catheter. This can be seen only if the catheter is radio-opaque (Doering et al., 1967), and it appears that unfortunately even now not all types of catheter are radio-opaque. For final proof of the extravascular site of the catheter, injection of a marker dye, if there is immediate access to its drainage channels-for example, a thoracotomy drain or radio-opaque medium (which can be seen on $x$-ray film)may be made into the catheter.

It may be of value to know whether the pleural fluid is clear fluid (from the infusion) or blood (from the damaged vein) and to this end immediate tapping of the effusion with a syringe and No. 1 needle can be performed. If clear fluid only is obtained formal chest aspiration may be adequate to relieve the situation, though the possibility of thoracotomy and control of bleeding from the perforation must be borne in mind, and may be deemed to be the preferable initial treatment.

Finally, it cannot be overemphasized that most of the complications that arise from the use of central venous pressure catheters are due directly or indirectly to poor technique. Sepsis can be almost eradicated if strict precautions are taken, and the problem of hydrothorax stems from incorrect or unsuccessful attempts at venous catheterization. Blood should always be aspirated freely before a catheter is assumed to be in place-both at the time of insertion and later during use for injection of drugs. The catheter should also be fully stabilized after insertion by taping it firmly to the skin.

Common-sense precautions such as these may prevent a valuable technique from producing a life-threatening disaster.

We thank Mr. A. K. Yates and Mr. R. S. Lawrie for permission to report on cases under their care, and the staff of the intensive care unit for aid in collecting data.

\section{References}

Adar, R., and Mozes, M. (1970). Fournal of the American Medical Association, 214, 372.

Adar, R., and Mozes, M. (1971). British Medical fournal, 3. 746.

Arnold, S., Feather, R. S., and Gibbs, E. (1973). British Medical fournal, 1,

Aulebacher, C. E. (1970). Fournal of the American Medical Association, 214, 372 .

Bolasny, B. L., Shepard, G. H., and Scott, H. W. (1970). Surgery, Gynecology and Obstetrics, 130, 342 .

Colvin, M. P., Blogg, C. E., Savage, T. M., Jarvis, J. D., and Strunin, L. (1972). Lancet, 2, 317.

Darrell, J. H., and Garrod, L. P. (1969). British Medical fournal, 2, 481. Doering, R. B., Stemmer, E. A., and Connolly, J. E. (1967). American fournal of Surgery, 114, 259 .

English, I. C. W., Frew, R. M., Piggott, J. P., and Zaki, M. (1969). Anaesthesia, 24, 521 .

Henzel, J. H., and DeWeese, M. S. (1971). American fournal of Surgery, 121, 600.

Jernigan, W. R., Gardner, W. C., Mahr, M. M., and Milburn, J. L. (1970). Surgery, Gynecology and Obstetrics, 130, 520

Latimer, R. D. (1971). British fournal of Hospital Medicine, 5, 369.

Mahaffey, J. E., and Witherspoon, S. M. (1966). Anesthesiology, 27, 198.

Northfield, T. C., and Smith, T. (1970). Lancet, 2,584 .

Thomas, C. S., Carter, J. W., and Lowder, S. C. (1969). Archives of Surgery, 98, 217 .

Walker, M. M., and Saunders, R. C. (1969). Anaesthesia, 24, 453.

Walker, M. M., and Saunders, R. C. (1969). Anaesthesia, 24, 453. Wilmore, D. W., and Dudrick, S. J. (1969). Archives of Surgery, 98, 256.

\section{PRELIMINARY COMMUNICATIONS}

\section{Diabetes in Mice after Coxsackie $B_{4}$ Virus Infection}

\author{
T. J. COLEMAN, D. R. GAMBLE, K. W. TAYLOR
}

British Medical fournal, 1973, 3, 25-27

\section{Summary}

The intraperitoneal inoculation of $\mathrm{CD}_{1}$ mice with Coxsackie virus $B_{4}$ resulted in the raising of blood sugar levels to diabetic values 12 days after the administration of the virus. Serum insulin remained inappropriately low. Light microscopy changes in the islets of Langerhans showed mononuclear cell infiltration of the islets and marked degranulation of the $\beta$ cells. The acinar tissue appeared to be little changed. It is concluded that Coxsackie $B_{4}$ virus may cause a diabetic state compatible with islet cell damage.

School of Biological Sciences, University of Sussex, Brighton, Sussex BN1 9QG

T. J. COLEMAN, M.B., B.s., Research Assistant

K. W. TAYLOR, M.B., PH.D., Reader in Biochemistry

Public Health Laboratory, West Park Hospital, Epsom, Surrey D. R. GAMBLE, M.B., M.C.PATH., Director

\section{Introduction}

In recent years much interest has been aroused by reports of virus-induced diabetes in animals. Diabetes complicating foot-and-mouth disease in cattle was reported in Italy (Barboni and Manocchio, 1962) and Craighead and McLane (1968) gave conclusive evidence that a heart-adapted strain of encephalomyocarditis virus (E.M.C.) causes diabetes in certain strains of mice. Burch et al. (1971) reported islet and acinar cell damage in mice after Coxsackie $\mathbf{B}_{4}$ and $\mathbf{B}_{1}$ virus infections, though blood sugar and insulin levels were not recorded.

We now present data showing the development of diabetes in mice after Coxsackie $B_{4}$ virus inoculation.

\section{Methods}

Male $\mathrm{CD}_{1}$ mice (Charles River Mouse Farms, England) were 8-9 weeks old at the time of inoculation. They were given free access to food and water at all times.

The Coxsackie $B_{4}$ virus was a prototype strain propagated in tissue culture fluid and titrated in suckling mice less than 24 hours old. Each test animal was inoculated intraperitoneally with $0.2 \mathrm{ml}$ of virus suspension containing 100 $\mathrm{LD}_{50}$. Control animals were inoculated with $0.2 \mathrm{ml}$ of sterile tissue culture maintenance medium.

Blood sugar estimations were made using tail vein blood and using the GOD-Perid method (Boehringer-Mannheim G.m.b.H.). 